\title{
I.UMIBUNG
}

\section{ANALISA PENDAPATAN PETANI INTEGRASI PADI-SAPI PADA KELOMPOK TANI PEMUDA SETIA NAGARI SIMALANGGANG}

\author{
Mukhlis ${ }^{1}$ \\ ${ }^{1)}$ Program Studi Agribisnis Politeknik Pertanian Negeri Payakumbuh \\ Korespondensi: mukhlisagus2014@gmail.com
}

Diterima

Disetujui

Diterbitkan

\begin{abstract}
ABSTRAK
Penelitian ini didasarkan pada sistem pertanian terpadu yang merupakan sistem pertanian yang didasarkan pada konsep daur ulang biologis antara tanaman, perikanan dan ternak. Implementasi sistem integrasi padi-sapi mampu memberikan manfaat bagi penggunaan pupuk kandang yang dapat meningkatkan produktivitas, mengurangi biaya produksi dan meningkatkan pendapatan petani. Jerami padi tidak digunakan secara optimal, mahal dan ketersediaan pupuk urea yang langka, limbah ternak belum dimanfaatkan dengan baik dan limbah kulit kakao belum digunakan sebagai pakan ternak. Tujuan dari penelitian ini adalah: 1) untuk mengetahui peningkatan keuntungan usaha tani dari adopsi sistem usaha tani terpadu dibandingkan dengan sistem konvensional dan 2) untuk menganalisis kelayakan usaha tani dengan penerapan sistem usaha tani terpadu dan sistem konvensional. Kesimpulan dari penelitian ini adalah sebagai berikut: 1) Penerimaan dan keuntungan dari usaha tani konvensional kepada usaha tani dengan sistem pertanian terpadu adalah meningkat. Peningkatan penerimaan selama 6 bulan dari Rp 675 juta menjadi Rp 792,12 juta yaitu meningkat sebesar Rp 117,12 juta atau sebesar 17,35\%. Peningkatan keuntungan selama 6 bulan dari Rp 203,57 juta menjadi Rp 259,02 yaitu meningkat sebesar Rp 55,45 juta atau setara dengan $27,24 \%$. 2) Nilai $\mathrm{R} / \mathrm{C}$ ratio dan profitabilitas dari usaha tani sistem integrasi padi-sapi terintegrasi sebesar 1,49 dan 48,59\%. Sedangkan nilai R/C ratio dan profitabilitas usaha tani sapi potong dengan pemeliharaan secara konvensional 25 ekor selama enam bulan adalah sebesar 1,43 dan $43,18 \%$. Nilai $\mathrm{R} / \mathrm{C}$ ratio dan profitabilitas menunjukkan bahwa bisnis ini layak.
\end{abstract}

Keywords: pendapatan, usaha tani, terpadu, padi, sapi

\begin{abstract}
This research is based on by the integrated farming system which is an agricultural system that is based on the concept of recycling between businesses biological crops, fisheries and livestock. Implementation of the system integration of rice-cattle are able to provide benefits for the use of manure that can increase productivity, reduce production costs and increase farmers' income. Rice straw is not used optimally, expensive and scarce availability of urea fertilizer, livestock waste has not been put to good use and waste cocoa skin has not been used as animal feed. The purpose of this study are: 1) To Know increase farm profits adoption of integrated farming system compared with conventional systems and 2) to analyze
\end{abstract}




\section{I.UMIBUNG}

the feasibility of farming with the application of integrated farming system and the conventional system. The conclusion of this study are as follows: 1) Revenue and profit from conventional farming to the maintenance of integrated farming system maintenance has increased. Increasing revenue during the six months of IDR 675 million increase to IDR 792.12 million is an increase of IDR 117.12 million or by $17.35 \%$. The increase in benefit during the six months of IDR 203.57 million increased to IDR 259.02 namely an increase of IDR 55,45 million or equal to $27.24 \%$. 2) The value of $R / C$ ratio and profitability of farm maintenance integrated farming system of rice-cattle at 1.49 and $48.59 \%$. While the value of $R / C$ ratio and profitability of beef cattle farming in the conventional maintenance 25 cattle during the six months amounted to 1.43 and $43.18 \%$. Rated $R / C$ ratio and profitability indicates that the business is feasible.

Keywords: income, farming, integrated, rice, cattle

\section{PENDAHULUAN}

Pembangunan pertanian tanaman pangan terus ditingkatkan untuk menuju tercapainya swasembada pangan daerah, dalam rangka meningkatkan pendapatan petani dan keluarganya, memperluas kesempatan kerja serta untuk memenuhi kebutuhan daerah melalui pertanian tanaman pangan. Pemerintah telah menempuh berbagai kebijakan pokok yaitu intensifikasi, ekstensifikasi, diversifikasi dan rehabilitasi secara serasi dan merata untuk mencapai pertanian yang tangguh. Masalah pembangunan ekonomi yang kompleks, mencakup pendapatan rakyat rendah, tingkat kemiskinan relatif tinggi, pengangguran tinggi, ketimpangan ekonomi, pembangunan ekonomi daerah yang berjalan lambat, utang luar negeri relatif tinggi, kelangkaan energi, ketahanan pangan keropos, dan kemerosotan mutu lingkungan hidup. Solusi yang tepat bagi masalah pembangunan ekonomi adalah penerapan pertanian terpadu atau pertanian integrasi.

Sistem pertanian terpadu adalah Sistem pertanian terpadu yang didasarkan pada konsep daur ulang biologis antara usaha tanaman, perikanan dan peternakan. Sistem pertanian terpadu adalah suatu sistem pengelolaan tanaman, hewan ternak dan ikan dengan lingkungannya untuk menghasilkan suatu produk yang optimal dan sifatnya cenderung tertutup terhadap masukan luar (Nurcholis dan Supangkat, 2011; Soputan, 2012; Nurhaedah, 2013). Penerapan sistem integrasi padi-ternak sapi (SIPT) mampu memberikan keuntungan karena penggunaan pupuk kandang yang bisa meningkatkan produktivitas, mengurangi biaya produksi dan meningkatkan pendapatan petani. Kontribusi pendapatan dari SIPT terhadap pendapatan total rumah tangga petani cukup tinggi. Kemudian SIPT juga dapat mengoptimalkan pemanfaatan sumberdaya lokal seperti pemanfaatan jerami sebagai pakan 


\section{I.UMIBUNG}

ternak dan kotoran sapi sebagai pupuk organik, sehingga tidak ada limbah yang terbuang (Suwandi, 2005; Handayani, 2009; Tumewu et al, 2014; Fitriani dan Lutfi, 2018).

Produksi jerami padi dapat mencapai 12-15 ton per hektar per panen, bervariasi tergantung pada lokasi dan jenis varietas tanaman padi yang digunakan. Jerami padi yang dihasilkan dapat digunakan sebagai pakan sapi dewasa sebanyak 2-3 ekor sepanjang tahun dan pada lokasi yang mampu panen 2 kali setahun akan dapat menunjang kebutuhan pakan berserat untuk 4 - 6 ekor per ha sawah. Dengan luas areal sawah mencapai 23.769 ha, secara matematis walau hanya mengandalkan jerami sebagai sumber pakan ternak, di Kabupaten Lima Puluh Kota seharusnya dapat dipelihara ternak sapi sebanyak 100.000 s.d. 150.000 ekor (Yunilas, 2009). Kondisi ini menunjukkan bahwa Kabupaten Lima Puluh Kota memiliki sumber pakan hewan berupa jerami yang sangat berlimpah.

Kelompok Tani Pemuda Setia didirikan sejak tahun 2011 yang berlokasi di Balai Rupi, Nagari Simalanggang, Kecamatan Payakumbuh, Kabupaten Lima Puluh Kota. Kelompok tani ini terdiri dari 19 orang, yang diketuai oleh Isra. Masing-masing anggota dalam kelompok ini memiliki mata pencarian dari bertani (sawah, ladang dan beternak). Anggota kelompok tani ini masing-masing memiliki 0,25-1,5 ha lahan sawah dengan total 14,3 ha dan memiliki lahan kering masing-masing 0,25-2 ha dengan total 17 ha. Kemudian masing-masing anggota kelompok memiliki ternak sapi 1-4 ekor, dengan total sapi dimiliki 42 ekor, 4 ekor kerbau, 9 ekor kambing, 380 itik dan 337 ayam.

Permasalahan yang dihadapi kelompok tani pemuda setia adalah kurangnya introduksi iptek yang berdampak pada tidak terukurnya keberhasilan dan efisiensi usaha pertanian dan peternakan. Permasalahan tersebut meliputi: 1) Jerami yang belum dimanfaatkan secara optimal; 2) Mahal dan langkanya ketersediaan pupuk urea; 3) Limbah ternak belum termanfaatkan dengan baik. Berdasarkan latar belakang dan permasalahan di atas, maka dapat dirumuskan masalah penelitian sebagai berikut:

1. Berapa peningkatan pendapatan petani pada kelompok tani pemuda setia dengan penerapan sistem pertanian terpadu dibandingkan dengan pertanian sistem konvensional

2. Bagaimana kelayakan usaha tani pada kelompok tani pemuda setia antara penerapan sistem pertanian terpadu dengan pertanian sistem konvensional

Berdasarkan permasalahan yang dihadapi, maka perlu dilakukan penelitian tentang "Analisa Pendapatan Petani Integrasi Padi-Sapi pada Kelompok Tani Pemuda Setia Nagari Simalanggang." 


\section{I.UMIBUNG}

Adapun tujuan dari penelitian analisa pendapatan petani integrasi padi-sapi kelompok tani pemuda setia Nagari Simalanggang adalah sebagai berikut:

1. Untuk mengetahui peningkatan pendapatan petani pada kelompok tani pemuda setia nagari Simalanggang dengan penerapan sistem pertanian terpadu dibandingkan dengan pertanian sistem konvensional

2. Untuk menganalisa kelayakan usaha tani kelompok tani pemuda setia Nagari Simalanggang dengan penerapan sistem pertanian terpadu dibandingkan pertanian dengan sistem konvensional

\section{METODOLOGI PENELITIAN}

Penelitian dilakukan dengan cara survey di Nagari Simalanggang Kecamatan Payakumbuh Kabupaten Lima Puluh Kota pada kelompok tani pemuda setia Nagari Simalanggang Kecamatan Payakumbuh, dimana pemilihan daerah penelitian ini dilakukan dengan cara purposive methode atau sengaja (Sugiyono, 2013). Terpilihnya daerah tersebut dengan dasar pertimbangan: Daerah tersebut belum pernah diadakan penelitian tentang topik yang sama. Pengambilan data penelitian dilakukan pada bulan April tahun 2019 selama satu bulan. Metode analisa data menggunakan metode dekriptif kuantitatif dengan menggunakan analisa finansial yaitu analisa biaya dan penerimaan usaha tani, kemudian dilanjutkan analisa kelayak usaha tani dengan menggunakan analisa $\mathrm{R} / \mathrm{C}$ ratio dan analisa profitabilitas (tingkat keuntungan).

\section{HASIL DAN PEMBAHASAN}

\section{Analisa Finansial Usaha tani}

Berdasarkan data primer dari hasil survey dan hasil perhitungan analisa finansial usaha tani pemeliharaan sapi potong, maka terlihat jelas bahwa terjadi peningkatan penerimaan dan pendapatan dari usaha tani pemeliharaan secara konvensional ke pemeliharaan sistem integrasi 25 ekor sapi selama 6 bulan. Peningkatan penerimaan dari Rp 675.000.000 bertambah menjadi Rp 792.120.000 yakni terjadi peningkatan sebesar Rp 117.120.000 atau sebesar 17,35 \%. Peningkatan pendapatan dari Rp 203.570.475 bertambah menjadi Rp 259.015.743 yakni terjadi peningkatan sebesar Rp 55.445.268 atau sebesar 27,24 \%. Untuk lebih jelasnya dapat dilihat pada Tabel 1. 


\section{I.UMIRUNC}

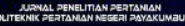

Tabel 1. Analisa Finansial usaha pemeliharaan sapi potong 25 ekor selama 6 bulan antara sistem integrated farming dengan konvensional

\begin{tabular}{|c|c|c|c|c|c|}
\hline \multirow{2}{*}{ NO } & \multirow{2}{*}{ KOMPONEN ANALISIS } & \multirow{2}{*}{$\begin{array}{l}\text { Kebutuh } \\
\text { an }\end{array}$} & \multirow{2}{*}{ Harga } & \multicolumn{2}{|c|}{ NILAI UANG (Rp 000) } \\
\hline & & & & Padi-Sapi & Sapi \\
\hline A. & \multicolumn{5}{|c|}{ 1. SARANA PRODUKSI SAPI } \\
\hline & a. Sapi bakalan & 25 & 13.000 & 325.000 & 325.000 \\
\hline & \multicolumn{5}{|l|}{ b. Makanan hijauan } \\
\hline & rumput (Karung) & 4.500 & 10.000 & 45.000 & 45.000 \\
\hline & c. Jerami padi (Kg) & 4.500 & 3.000 & 13.500 & 13.500 \\
\hline & d. Serbuk gergaji (karung) & 365 & 700 & 255 & 255 \\
\hline & \multicolumn{5}{|l|}{ e. Konsentrat, terdiri dari: } \\
\hline & 1). Dedak (Kg) & 9.000 & 2.000 & 18.000 & 18.000 \\
\hline & 2). Mineral (gram) & 225 & 5.000 & 1.125 & 1.125 \\
\hline \multicolumn{6}{|c|}{ 3). Kulit kakao } \\
\hline & (kg/ekor) & 9.000 & 300 & 2.700 & 2.700 \\
\hline \multicolumn{6}{|c|}{ f. Obat-obatan } \\
\hline & 1). Obat cacing (bolus) & 150 & 6.000 & 900 & 900 \\
\hline & 2). Vitamin & 70 & 150.000 & 10.500 & 10.500 \\
\hline \multicolumn{6}{|c|}{ g. Bahan kompos } \\
\hline & 1). EM-4 (btl) & 75 & 21.000 & 1.575 & \\
\hline & 2). Kapur Dolomit (kg) & 10.000 & 600 & 6.000 & \\
\hline & 3). Serbuk gergaji (krg) & 145 & 3.000 & 435 & \\
\hline & 4). Arang sekam (krg) & 72 & 10.000 & 720 & \\
\hline & 5). Thitonia (kg) & 42.000 & 300 & 12.600 & \\
\hline & 6). Karung (kg) & 3.000 & 3.000 & 9.000 & \\
\hline \multicolumn{6}{|c|}{ h. Bahan Budidaya lele } \\
\hline & 1). Bibit lele (ekor) & 1.300 & 500 & 650 & \\
\hline & 2). Pelet udang (kg) & 25 & 18.000 & 450 & \\
\hline & 3). Pelet ikan (kg) & 35 & 8.000 & 280 & \\
\hline & 4). Obat-obatan (paket) & 10 & 5.000 & 50 & \\
\hline \multicolumn{6}{|c|}{ 2. SARANA PRODUKSI PADI } \\
\hline & 1) Benih padi & & & 52 & \\
\hline & 2) Pupuk & & & 500 & \\
\hline & 3) Pestisida & & & 58 & \\
\hline & 4) Sewa tanah & & & 3.500 & \\
\hline & T O T A L ( A1 ) & & & $452.850,5$ & $416,980.5$ \\
\hline \multicolumn{6}{|c|}{ 1. ALAT-ALAT (buah) } \\
\hline & a. Kandang Sapi & 125 & 720.000 & 7.500 & 7.500 \\
\hline & b. Peralatan kandang & & & 1.500 & 1.500 \\
\hline & c. Peralatan Kompos & & & 117,15 & \\
\hline
\end{tabular}




\section{I.UMIBUNG}

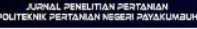

\begin{tabular}{|c|c|c|c|c|c|}
\hline & d. Rumah kompos & & & 137,50 & \\
\hline & e. Peralatan Biogas & & & 28,88 & \\
\hline & f. Kolam untuk lele & & & 18,98 & \\
\hline & 2. Penyusutan alat padi & & & 299,94 & \\
\hline & TO T A L ( A2) & & & $9.602,44$ & 9.000 \\
\hline & TO T A L (A) & & & $462.452,94$ & $425.980,5$ \\
\hline B & TENAGA KERJA (HKP) & & & & \\
\hline & 1. Ketua & 200 & 120.000 & 24.000 & 14.000 \\
\hline & 2. Anggota & 200 & 80.000 & 16.000 & 9.000 \\
\hline & 3. TK dalam keluarga & & & $1.555,25$ & \\
\hline & 4. TK luar keluarga & & & $3.710,15$ & \\
\hline & TO T A L (B ) & & & $45.265,40$ & 23,000 \\
\hline & TOT A L $(A+B)$ & & & $507.718,34$ & $448.980,5$ \\
\hline $\mathrm{C}$ & BIAYA TAK TERDUGA & & & $25.385,92$ & $22.449,03$ \\
\hline & TOTAL BIAYA & & & $533.104,26$ & $471.429,53$ \\
\hline & PENERIMAAN DAN & & & & \\
\hline & KEUNTUNGAN & & & & \\
\hline & 1. Sapi (ekor) & 25 & 120.000 & 675.000 & 675.000 \\
\hline & 2. Kompos (ton) & 140.000 & 600 & 84.000 & \\
\hline & 3. Biogas (kg) & 45 & 10.000 & 450 & \\
\hline & 4. Lele $(\mathrm{kg})$ & 360 & 22.000 & 7.920 & \\
\hline & 5. Gabah/padi & 7.500 & 3.300 & 24.750 & \\
\hline & Total Penerimaan (Rp) & & & 792.120 & 675.000 \\
\hline & PENDAPATAN & & & $259.015,74$ & $203.570,48$ \\
\hline
\end{tabular}

\section{Analisa Kelayakan Usaha Tani}

Analisa $\mathrm{R} / \mathrm{C}$ ratio

Analisa $\mathrm{R} / \mathrm{C}$ ratio usaha tani dengan integrated farming system

$$
\begin{aligned}
\mathrm{R} / \mathrm{C} \text { Ratio } & =\frac{\mathrm{TR}}{\mathrm{TC}} \\
& =\frac{\mathbf{7 9 2 . 1 2 0 . 0 0 0}}{\mathbf{5 3 3 . 1 0 4 . 2 5 7}} \\
& =1,49
\end{aligned}
$$

Analisa R/C ratio usaha tani konvensional

$$
\begin{aligned}
\mathrm{R} / \mathrm{C} \text { Ratio } & =\frac{\mathrm{TR}}{\mathrm{TC}} \\
& =\frac{\mathbf{6 7 5 . 0 0 0 . 0 0 0}}{\mathbf{4 7 1 . 4 2 9 . 5 2 5}} \\
& =1,43
\end{aligned}
$$




\section{I.UMIBUNG}

\section{Analisa Profitabilitas}

Analisa Tingkat Keuntungan usaha tani dengan integrated farming system

$$
\begin{aligned}
\text { Profitability } & =\frac{\mathrm{TR}-\mathrm{TC}}{\mathrm{TC}} \times 100 \% \\
& =\frac{\mathbf{7 9 2 . 1 2 0 . 0 0 0 - 5 3 3 . 1 0 4 . 2 5 7}}{\mathbf{5 3 3 . 1 0 4 . 2 5 7}} \times 100 \% \\
& =48,59 \%
\end{aligned}
$$

Analisa Tingkat Keuntungan usaha tani konvensional

$$
\begin{aligned}
\text { Profitability } & =\frac{\mathrm{TR}-\mathrm{TC}}{\mathrm{TC}} \times 100 \% \\
& =\frac{\mathbf{6 7 5 . 0 0 0 . 0 0 0 - 4 7 1 . 4 2 9 . 5 2 5}}{\mathbf{4 7 1 . 4 2 9 . 5 2 5}} \times 100 \% \\
& =43,18 \% .
\end{aligned}
$$

\section{KESIMPULAN DAN SARAN}

Berdasarkan hasil penelitian yang telah dilakukan dan sesuai dengan tujuan dari penelitian, dapat ditarik beberapa kesimpulan sebagai berikut:

1. Penerimaan dan keuntungan dari usaha tani pemeliharaan secara konvensional ke pemeliharaan penerapan Integrated Farming Systems mengalami peningkatan. Peningkatan penerimaan selama 6 bulan dari Rp 675.000.000 bertambah menjadi Rp 792.120.000 yakni terjadi peningkatan sebesar Rp 117.120.000 atau sebesar 17,35\%. Peningkatan pendapatan selama 6 bulan dari Rp 203.570 .475 bertambah menjadi Rp 259.015.743 yakni terjadi peningkatan sebesar Rp 55.445.268 atau sebesar $27,24 \%$.

2. Nilai $\mathrm{R} / \mathrm{C}$ ratio dan profitabilitas usaha tani pemeliharaan sapi potong penerapan integrated farming system adalah sebesar 1,49 dan 48,59\%. Sedangkan Nilai R/C ratio dan profitabilitas usaha tani pemeliharaan sapi potong secara konvensional adalah sebesar 1,43 dan $43,18 \%$. Nilai $\mathrm{R} / \mathrm{C}$ ratio dan profitabilitas tersebut menunjukkan bahwa usaha tersebut layak dilaksanakan.

\section{REFERENSI}

Fitriani, R., \& Lutfi, U. 2018. Pemanfaatan Jerami Jagung Yang Diinokulasi Fungi Trichoderma sp. Sebagai Pakan Kambing Kacang Dengan Tambahan Daun Gamal. Journal of Livestock and Animal Health, 1(1), 20-24. https://doi.org/10.32530/jlah.v1i1.29 


\section{I.UMIBUNG}

Handayani, S. 2009. Model integrasi tanaman-ternak di Kabupaten Donggala Provinsi Sulawesi Tengah: Pendekatan Optimasi Program Linier. [Disertasi] Bogor. Sekolah Pascasarjana Institut Pertanian Bogor.

Nurcholis dan Supangkat. 2011. Development of Integrated Farming System To Control Agricultural Land Transfer Function. Proceedings of the National Conference on Agriculture. Bengkulu University. Bengkulu.

Nurhaedah. 2013. Optimization of Public Land to the Implementation of Integrated Farming Pattern. Forestry Research Institute of Makassar. Journal Technical Info EBONI Vol. 10 No. 2, Desember 2013: 107-116. Makassar.

Yunilas, 2009, Bioteknologi jerami melalui fermentasi sebagai bahan pakan ternak ruminansia. Karya Ilmiah, Departemen Peternakan, Fakultas Pertanian, USU.

Soputan, J.E.M. 2012. The integration pattern of Pigs With Sweet Potato that Environmental in Minahasa. Dissertation. Bogor. Postgraduate School of Bogor Agricultural University.

Sugiyono. 2013. Research Methods of Quantitatif and Qualitatif dan Research and Development. Alfabeta Publishing. Bandung.

Suwandi. 2005. Keberlanjutan Usaha Tani Pola Padi Sawah-Sapi Potong Terpadu di Kabupaten Sragen: Pendekatan Rap-CLS. [Disertasi]. Bogor. Sekolah Pascasarjana Institut Pertanian Bogor.

Tumewu, J.M., Panelewen, V.V. dan Mirah, A.D. 2014. Analisis Usaha Tani Terpadu Sapi Potong dan Padi Sawah Kelompok Tani "Keong Mas" Kecamatan Sangkub, Kabupaten Bolaang Mongondow Utara (Studi Kasus). Jurnal ZOOTEK 34 (2): 1-9. 